\title{
ANALISIS PENGENDALIAN KUALITAS PEMBUATAN WELLHUB DENGAN PENDEKATAN LEAN SIX SIGMA
}

\author{
HM. Ibnu Mastur ${ }^{1}$, Nizar Filiawan Aji ${ }^{2}$ \\ Jurusan Teknik Industri Fakultas Teknologi Industri, ${ }^{1,2)}$ \\ Universitas Islam Indonesia Kampus UII Terpadu. \\ Jl. Kaliurang km 14,5 Sleman, Yogyakarta \\ Email:835220102@staf.uii.ac.id ${ }^{l}$
}

\begin{abstract}
Wheel hub that is produced by PT. Yogya Presisi Tekniktama is a car wheel accessory that requires right size and striking shape, hence the need for accuracy of size is a must, so control should be maintained. Quality control is the way to determine the suitability between the standards that have been determined with the finished product that has been produced by PT. Yogya Presisi Teknikatama. The Six Sigma Motorolla method is employed for quality control. From the diameter of Well hub, it can be identified that there is still DPMO of 42,700, the ability of the process is considered low enough with Cpm $=0.675$, and the production process is unstable. While, defective products are caused by 5 types of origins with DPMO of 34.126. The highest cause of defective products is caused by "Siloek". Proposed improvements to improve product quality, among others are; the machine repair on its holding pressure. While, in terms of method, the temperature of heater should be decreased to between $1-5^{\circ} \mathrm{C}$.
\end{abstract}

Keywords: Well Hub, Six Sigma Motorola.

\section{PENDAHULUAN}

Semakin majunya perkembangan zaman dan akan memasuki era perdagangan bebas serta globalisasi ekonomi dunia sekarang ini, tuntutan akan mutu produk yang tinggi dengan harga yang bersaing cenderung meningkat. Untuk dapat menghasilkan produk yang berkualitas tinggi hanya dapat dicapai dengan serangkaian pengendalian proses produksi yang baik, konsisten dan ketat. Selain itu, konsumen semakin sadar akan hak - haknya untuk memperoleh produk dengan mutu yang sesuai dengan harga yang dibayar (Naniek, 2007).

Peranan kualitas pada suatu produk sangat penting dalam situasi pemasaran yang semakin bersaing, karena dapat mempengaruhi maju atau tidaknya perusahaan. Perusahaan bukan hanya memperhatikan kuantitas produk yang dihasilkan tetapi juga kualitas dari produk tersebut. Bagi perusahaan yang tidak memperhatikan kualitas produk yang dihasilkan akan mengalami banyak kendala dalam pemasarannya, sehingga produk kurang laku dan mengalami penurunan penjualan.

PT.Yogya Presisi Teknikatama Industri (PT.YPTI) adalah sebuah perusahaan yang bergerak dalam bidang industri manufaktur dengan produk yang dihasilkan berupa mold dan sparepart kendaraan. Kualitas dan kapasitas produksi yang ada juga harus tetap terjaga namun tidak menutup kemungkinan masih terjadi kecacatan produk dalam proses produksi. Angka kecacatan produk harus ditekan seminimal mungkin agar kepercayaan pelanggan dapat terjaga.

Untuk itu perlu diadakan pengendalian kualitas terhadap produk yang telah diproduksi sehingga dapat mengurangi produk cacat. Kualitas diartikan sebagai 
tingkat kesesuaian produk dengan standar yang telah ditetapkan (Alisjahbana, 2005), sehingga produk dengan kualitas yang baik akan dihasilkan dari proses yang baik pula, serta sesuai dengan standar kualitas yang telah ditentukan (Gunawan, 2013).

Salah satu metode yang akhir- akhir ini muncul dengan tujuan agar dapat mempertahankan eksistensi perusahaan adalah Lean Six Sigma. Konsep Lean Six Sigma saat ini sangat populer di negara negara industri maju terutama Amerika Serikat dan Kanada. .Tujuan dari penelitian ini adalah menjaga kualitas produk yaitu menjaga produk agar sesuai dengan spesifikasi yang telah ditetapkan.

\section{TINJAUAN PUSTAKA}

\subsection{Pengertian Quality ( Kualitas )}

Keistimewaan atau keunggulan suatu produk dapat diukur melalui tingkat kepuasan pelanggan. Salah satunya dapat dilihat dari sisi kualitas produk itu sendiri. Semakin baik kualitas yang ditawarkan, maka pelanggan akan semakin merasa puas. Kualitas akan selalu berfokus pada pelanggan (culstomer focused quality).

Berdasarkan definisi di atas pada dasarnya kualitas mengacu kepada pengertian pokok berikut : (Gaspersz, 2002 : 5). Kualitas terdiri dari sejumlah keistimewaan produk, baik keistimewaan langsung maupun keistimewaan atraktif yang memenuhi keinginan pelanggan dan dengan demikian memberikan kepuasan atas penggunaan produk itu. Kualitas terdiri dari segala sesuatu yang bebas dari kekurangan atau kerusakan.

\subsection{Pengertian Pengendalian}

Pengendalian adalah semua kegiatan (usaha) untuk menjamin agar hasil dari pelaksanaan sesuai dengan tujuan yang telah ditetapkan dalam rencana. Control sendiri mencakup quality control dan cost control. Pengendalian dapat diartikan sebagai berikut:

1. Pengendalian merupakan proses pengukuran kinerja, membandingkan antara hasil sesungguhnya dengan rencana serta mengambil tindakan pembetulan yang diperlukan. (Schermerhorn, 2003: 13).

2. Pengendalian merupakan proses mengukur dan mengevaluasi pelaksanaan nyata setiap komponen organisasi dan melaksanakan tindakan korektif jika diperlukan. (Suprianto, 2001: 10).

3. Pengendalian adalah mengatur agar kegiatan - kegiatan produksi sesuai dengan apa yang direncanakan. (Sukanto, $2000: 10$ ).

Dari pengertian pengendalian di atas dapat disimpulkan bahwa pengendalian dapat dilakukan apabila ada perencanaan atau standar yang telah ditetapkan dan diharapkan penyimpangan - penyimpangan dapat dihindari. Pengendalian juga untuk melihat sebab - sebab timbulnya penyimpangan.

\subsection{Six Sigma Motorolla}

Menurut Gaspersz (2005:310) six sigma merupakan suatu visi dalam peningkatan kualitas menuju target 3,4 kegagalan per sejuta kesempatan untuk setiap transaksi produk barang dan jasa. Sehingga six sigma merupakan metode dalam pengendalian kualitas yang dramatik dan terobosan baru dalam bidang manajemen kualitas. Six sigma merupakan suatu metode yang sistematis dan terukur yang dapat digunakan untuk perbaikan proses dan pengembangan produk baru yang didasarkan pada metode statistik dan ilmiah untuk mengurangi jumlah cacat yang telah didefinisikan oleh konsumen.

Six sigma mulanya diperkenalkan oleh perusahaan telekomunikasi asal Amerika Serikat Motorola pada tahun 1980-an yang dikembangkan dalam rangka untuk melakukan perbaikan kualitas dan mengeliminasi cacat - cacat produk secara sistematis. Sigma merupakan suatu istilah dalam statistik untuk menunjukkan penyimpangan standar, suatu indikator dari tingkat variasi dalam seperangkat 
pengukuran atau proses. Six sigma merupakan konsep statistik yang mengukur suatu proses yang berkaitan dengan cacat (defect) pada level enam (six)sigma, hanya terjadi 3,4 kejadian cacat dari sejuta peluang. Six sigma pun merupakan falsafah manajemen yang berfokus untuk menghapus cacat dengan cara menekankan pemahaman, pengukuran, dan perbaikan proses (Brue 2002). Brue (2002) juga mengatakan bahwa cacat (defect) merupakan ciri yang dapat diukur dari suatu proses atau outputnya yang tidak berada di dalam batas - batas yang dapat diterima pelanggan.
Pendekatan pengendalian proses 6Sigma Motorola (Motorola's Six Sigma process control) mengizinkan adanya pergeseran nilai rata-rata (mean) setiap CTQ individual dari proses industri terhadap nilai spesifikasi target (T) sebesar 1,5-Sigma. Konsep Six Sigma Motorola berbeda dari konsep Six Sigma dalam distribusi normal yang umum dipahami selama ini yang tidak mengizinkan pergeseran dalam nilai rata-rata (mean) dari proses. Perbedaan ini dapat ditunjukan pada tabel 2.1.

Tabel 1. Perbedaan True Six Sigma dan Six Sigma Motorolla

\begin{tabular}{|c|c|c|c|c|c|}
\hline \multicolumn{3}{|c|}{$\begin{array}{c}\text { True Six Sigma Process } \\
\text { (Normal Distribution Centered) }\end{array}$} & \multicolumn{3}{|c|}{$\begin{array}{c}\text { Motorola's Six Sigma process } \\
\text { (Normal Distribution Shifted 1,5 Sigma) }\end{array}$} \\
\hline $\begin{array}{c}\text { Batas } \\
\text { spesifikasi } \\
\text { (LSL-USL) }\end{array}$ & $\begin{array}{l}\text { Presentation } \\
\text { Yang } \\
\text { Memenuhi }\end{array}$ & $\begin{array}{c}\text { DPMO } \\
\text { (kegagalan/ } \\
\text { Sejuta }\end{array}$ & $\begin{array}{c}\text { Batas } \\
\text { spesifikasi } \\
\text { (LSL-USL) }\end{array}$ & $\begin{array}{c}\text { Presentation } \\
\text { Yang } \\
\text { Memenuhi }\end{array}$ & $\begin{array}{c}\text { DPMO } \\
\text { (kegagalan/ } \\
\text { Sejuta }\end{array}$ \\
\hline & $\begin{array}{l}\text { Spesifikasi } \\
\text { (LSL-USL) }\end{array}$ & Kesempatan & & $\begin{array}{l}\text { Spesifikasi } \\
\text { (LSL-USL) }\end{array}$ & kesempatan \\
\hline \pm 1 Sigma & $68,27 \%$ & 317.300 & \pm 1 Sigma & $30,8538^{\prime} \%$ & 691.462 \\
\hline \pm 2 Sigma & $95,45 \%$ & 45.500 & \pm 2 Sigma & $69,1462^{\prime} \%$ & 308.538 \\
\hline \pm 3 Sigma & $99,73 \%$ & 2.700 & \pm 3 Sigma & $93,3193^{\prime} \%$ & 66.807 \\
\hline \pm 4 Sigma & $99,9937^{\prime} \%$ & 63 & \pm 4 Sigma & $93,3790^{\prime} \%$ & 6.210 \\
\hline \pm 5 Sigma & $99,999943^{\prime} \%$ & 0,57 & \pm 5 Sigma & $99,9767^{\prime} \%$ & 233 \\
\hline \pm 6 Sigma & $99,9999998^{\prime} \%$ & 0,002 & \pm 6 Sigma & $99,99966^{\prime} \%$ & 3.4 \\
\hline
\end{tabular}

(Sumber : Gaspersz, 2002)

Nilai pergeseran 1,5 Sigma ini diperoleh dari hasil penelitian Motorola atas proses dan sistem industri, dimana menurut hasil penelitian bahwa sebagus-bagusnya suatu proses industri tidak akan $100 \%$ berada pada satu titik nilai target, tetapi akan ada pergeseran sebasar rata-rata 1,5 Sigma dari nilai tersebut. Gambar konsep Six Sigma dengan pergeseran distribusi normal 1,5 Sigma dapat dilihat pada gambar di bawah ini :

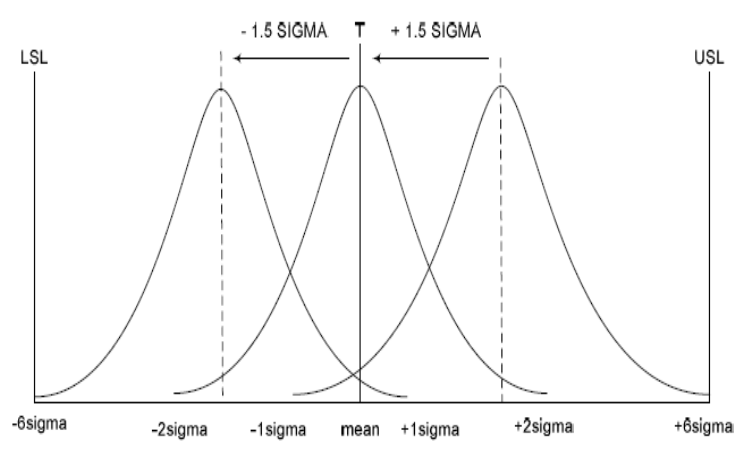

Gambar 1. Konsep Six Sigma.

Dalam melakukan implementasi six sigma digunakan langkah - langkah Define,Measure, Analyze, Improve dan Control yang biasa disingkat dengan DMAIC. 


\section{METODE PENELITIAN}

\subsection{Pengumpulan dan Pengolahan Data}

\subsubsection{Data Variabel}

Penelitian dilakukan di PT Yogya Presisi Teknikatama dengan produknya asesoris mobil yaitu Well Hub. Pengumpulan data dilakukan dengan; Pengukuran langsung, Wawancara, dan Data sekunder. Pengolahan data dilakukan dengan cara, yaitu :

1. Menghitung nilai DPMO, nilai Sigma, dan nilai Kemampuan proses data variabel.

2. Menghitung nilai DPMO dan nilai Sigma data atribut.

Analisa penelitian ini di gunakan untuk menentukan faktor - faktor penyebab cacat produk dengan diagram sebab - akibat serta menguji stabilitas proses data variable.

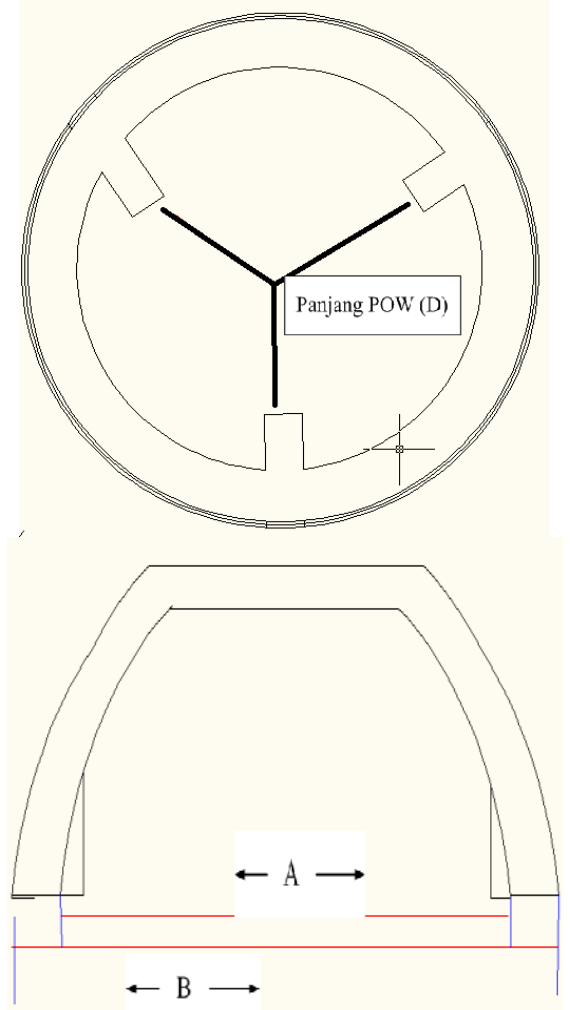

Gambar 2. Produk Well Hub.
Tabel.2 Spesifikasi Produk Well Hub.

\begin{tabular}{|c|c|c|c|c|}
\hline No & $\begin{array}{c}\text { Panjang / } \\
\text { Dimensi }\end{array}$ & $\begin{array}{l}\text { Upper } \\
(\mathrm{mm})\end{array}$ & $\begin{array}{c}\text { Standard } \\
(\mathrm{mm})\end{array}$ & $\begin{array}{l}\text { Lower } \\
(\mathrm{mm})\end{array}$ \\
\hline 1 & $\begin{array}{c}\text { POW } \\
(\text { dalam) }\end{array}$ & 74 & 70 & 66 \\
\hline 2 & A & 65 & 64 & 63 \\
\hline 3 & B & 67.5 & 66 & 64.5 \\
\hline
\end{tabular}

Menghitung harga DPMO, Nilai Sigma, dan Nilai Kemampuan Proses.

Tabel.3 Menghitung harga DPMO dan nilai sigma jari - jari (POW)

\begin{tabular}{ccccc}
\hline No & $\overline{(\boldsymbol{X}})$ & $(\mathbf{S}=\mathbf{R} / \mathbf{d} 2)$ & DPMO & SIGMA \\
\hline 1 & 70,48 & 1,117798796 & 8,496 & 3,89 \\
2 & 70,42 & 1,031814273 & 26,979 & 3,43 \\
3 & 69,52 & 0,773860705 & 27,034 & 3,42 \\
4 & 69,88 & 0,386930353 & 58,761 & 3,07 \\
5 & 69,02 & 1,332760103 & 11,819 & 3,77 \\
6 & 70,16 & 2,14961307 & 63,5 & 3,03 \\
7 & 73,68 & 3,353396389 & 47,992 & 3,13 \\
8 & 69,18 & 1,289767842 & 69,933 & 2,98 \\
9 & 70,62 & 1,504729149 & 13,413 & 3,71 \\
10 & 68 & 2,536543422 & 124,214 & 2,65 \\
11 & 71,3 & 5,846947549 & 50,446 & 3,14 \\
12 & 69,76 & 0,515907137 & 16,725 & 3,63 \\
13 & 69,25 & 4,514187446 & 38,122 & 3,27 \\
14 & 69,5 & 1,375752365 & 104,14 & 2,75 \\
15 & 71,82 & 2,665520206 & 22,122 & 3,51 \\
16 & 69,2 & 1,54772141 & 20,304 & 3,54 \\
17 & 72,34 & 3,482373173 & 35,126 & 3,31 \\
18 & 69,44 & 0,429922614 & 61,4863 & 3,04 \\
19 & 70,92 & 1,805674979 & 47,246 & 3,17 \\
20 & 71,4 & 1,37575239 & 15,84 & 3,65 \\
& $\overline{\bar{X}}=$ & S $=1,9518$ & 42,442 & 3,22 \\
Proses & 70,26 & & & \\
\hline
\end{tabular}

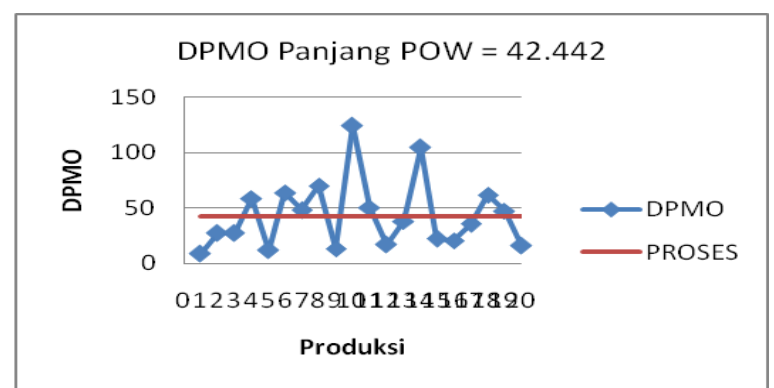

Gambar 3. Grafik DPMO Panjang POW. 


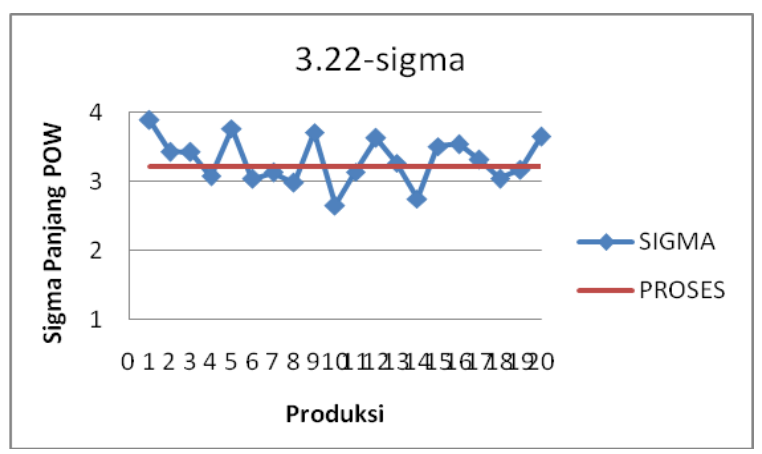

Gambar 4. Grafik Nilai Sigma Panjang POW.

Tabel.4 Menghitung Nilai DPMO, Nilai Sigma, dan Kemampuan Proses pada Variabel Jari - Jari (POW)

\begin{tabular}{|c|c|c|c|}
\hline No & Tindakan & Persamaan & $\begin{array}{c}\text { Hasil } \\
\text { Perhitungan }\end{array}$ \\
\hline 1 & $\begin{array}{l}\text { Proses apa yang ingin } \\
\text { anda tahu? }\end{array}$ & - & $\begin{array}{c}\text { Pembuatan Well } \\
\text { Hub } \\
\end{array}$ \\
\hline 2 & $\begin{array}{l}\text { Tentukan nilai batas } \\
\text { spesifikasi atas (upper } \\
\text { specification limit) }\end{array}$ & USL & $74 \mathrm{~mm}$ \\
\hline 3 & $\begin{array}{c}\text { Tentukan nilai batas } \\
\text { spesifikasi bawah (lower } \\
\text { specification limit) }\end{array}$ & LSL & $66 \mathrm{~mm}$ \\
\hline 4 & $\begin{array}{c}\text { tentukan nilai spesifikasi } \\
\text { target }\end{array}$ & $\mathrm{T}$ & $70 \mathrm{~mm}$ \\
\hline 5 & $\begin{array}{l}\text { Berapa nilai rata-rata } \\
\text { (mean) proses }\end{array}$ & $\overline{\bar{X}}$ & $70,276 \mathrm{~mm}$ \\
\hline 6 & $\begin{array}{c}\text { Berapa nilai standard } \\
\text { deviasi dari proses }\end{array}$ & $\mathrm{S}$ & 1,9518 \\
\hline 7 & $\begin{array}{c}\text { Hitung kemungkinan cacat } \\
\text { yang berada diatas nilai } \\
\text { USL per satu juta } \\
\text { kesempatan (DPMO) } \\
\end{array}$ & $\mathrm{P}\{\mathrm{z} \geq(\mathrm{USL}-\overline{\bar{X}}) / \mathrm{S}\} \times 1000000$ & 28,100 \\
\hline 8 & $\begin{array}{c}\text { Hitung kemungkinan cacat } \\
\text { yang berada dibawah nilai } \\
\text { LSL per satu juta } \\
\text { kesempatan (DPMO) } \\
\end{array}$ & $\mathrm{P}\{\mathrm{z} \leq(\operatorname{LSL}-\overline{\bar{X}}) / \mathrm{S}\} \times 1000000$ & 14,600 \\
\hline 9 & $\begin{array}{c}\text { Hitung kemungkinan cacat } \\
\text { per satu juta kesempatan } \\
\text { (DPMO) yang dihasilkan } \\
\text { pada proses diatas } \\
\end{array}$ & $=($ langkah 7) $+($ langkah 8) & 42,700 \\
\hline 10 & $\begin{array}{l}\text { Konversi DPMO (langkah } \\
\text { 9) ke dalam nilai sigma }\end{array}$ & - & 3,22 \\
\hline 11 & $\begin{array}{c}\text { Hitung kemampuan proses } \\
\text { diatas dalam ukuran nilai } \\
\text { sigma } \\
\end{array}$ & - & $\begin{array}{c}\text { Kapabilitas Proses } \\
\text { adalah } 3,22\end{array}$ \\
\hline 12 & $\begin{array}{l}\text { Hitung kapabilitas proses } \\
\text { diatas dalam indeks } \\
\text { kapabilitas proses }\end{array}$ & $C p m=\frac{U S L-L S L}{6 \sqrt{(\overline{\bar{X}}-\mathrm{T})^{2}+S^{2}}}$ & 0,675 \\
\hline
\end{tabular}




\subsection{Data Atribut}

\subsection{Menentukan Critical to Quality (CTQ)}

Pada penelitian ini penyebab produk cacatnya meliputi cacat jenis Silver st, Gashmark, Short Shot, Flowmark, dan Overcut.

\section{1.) Silver st}

Adalah jenis cacat yang terdapat bercak noda (salain warna dasar ) pada permukaan produk dapat disebabkan settingan pemanasan yang berlebih.

\section{2.) Gashmark}

Adalah jenis cacat yang pada permukaan produk seperti terdapat bayangan bekas adanya udara yang terperangkap dalam mold, dapat disebabkan setingan block lase yang berubah.

3.) Short Shot

Adalah jenis cacat yang pada bagian dalam tempat dudukan OWH ada yang tidak sempurna (biasanya jumlah kurang dan atau bentuk tidak sempurna), dapat disebabkan karena setingan material sehingga material kurang padat.

4.) Flowmark

Adalah jenis cacat pada permukaan produk terdapat seperti aliran material tambahan biasanya seperti rambut yang menempel. Bisa disebabkan karena locklase yang setingan nya kurang tepat.

5.) Overcut

Adalah jenis cacat pada produk terdapat bekas cutter sehingga permukaan tidak sempurna disebabkan oleh operator yang kurang presisi saat memotong.

Tabel 5 Karakteristik Produk Cacat

\begin{tabular}{cccc}
\hline Jenis & Total & Persen (\%) & Akumulasi(\%) \\
\hline Silver & 4672 & 68.78680801 & 68.78680801 \\
Gastmark & 762 & 11.21908127 & 80.00588928 \\
Shoot-short & 1255 & 18.47762073 & 98.48351001 \\
Flowmark & 89 & 1.310365135 & 99.79387515 \\
Overcut & 14 & 0.206124853 & 100 \\
\hline Total & 6792 & 100 & \\
\hline
\end{tabular}

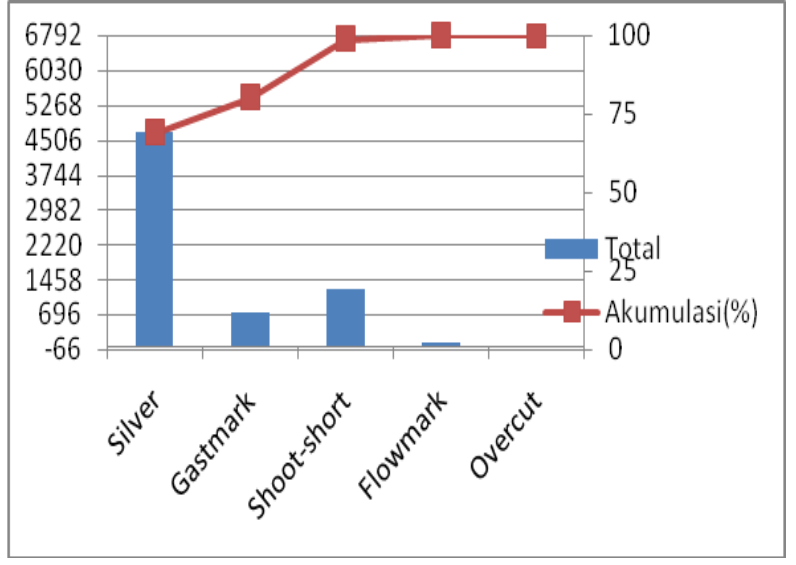

Gambar 5. Diagram Pareto Berdasarkan Jenis Cacat.

Dari diagram pareto diatas produk cacat yang paling banyak terjadi pada jenis cacat silver dengan total 4672 unit atau $68.78 \%$ dari keseluruhan produk cacat yang terjadi.

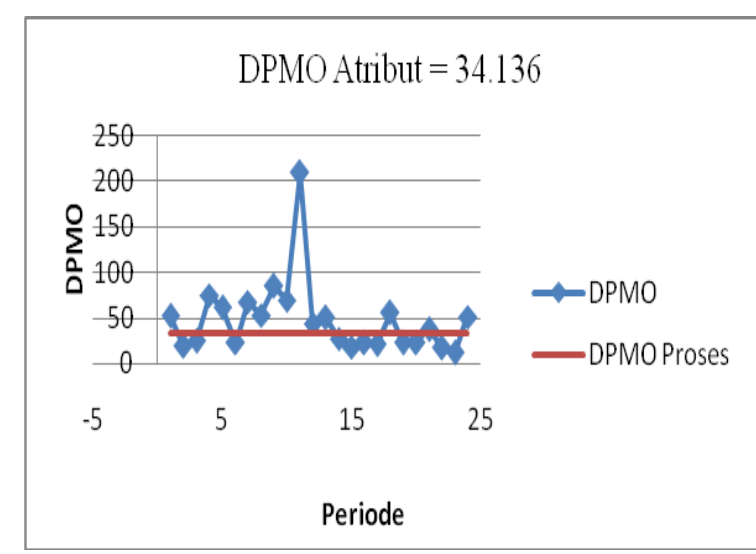

Gambar 6. Grafik Nilai DPMO.

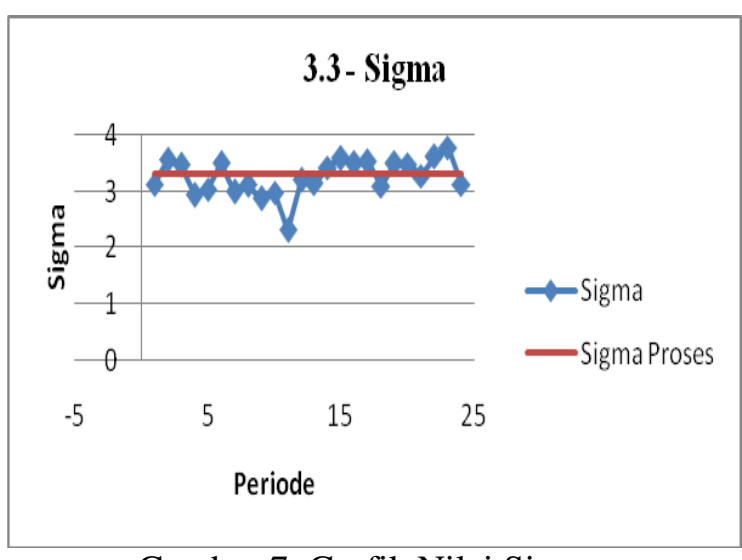

Gambar 7. Grafik Nilai Sigma. 


\section{HASIL DAN PEMBAHASAN}

\subsection{Data Atribut}

Dari diagram Pareto produk cacat yang paling banyak disebabkan oleh cacat jenis Silver st dengan total produk cacat 4672 unit dan prosentase $68.78 \%$ dari keseluruhan cacat yang terjadi.

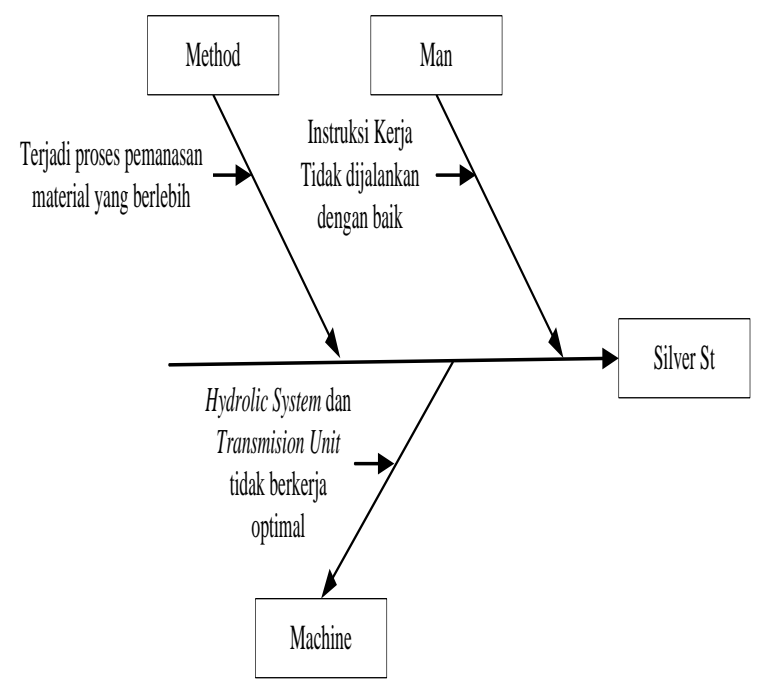

Gambar 7. Diagram Fishbone Silver St.

\subsection{Metode}

Pada SOP tercantum suhu ideal untuk membuat produk Well Hub adalah $115^{\circ} \mathrm{C}$ $125^{\circ} \mathrm{C}$, jika suhu terlalu tinggi maka akan terjadi cacat jenis Silver St dan jika suhu terlalu rendah (dingin) akan terjadi jenis cacat gashmark. Dari diagram pareto jenis cacat yang paling banyak terjadi adalah silver st sehingga dapat dipastikan pada proses produksi terjadi pemanasan yang berlebih yaitu sekitar $135 \mathrm{C}$, sehingga perlu ada penurunan suhu.

\subsection{Manusia / Operator}

Operator

\section{yang}

bekerja tidak

melaksanakan instruksi kerja beserta langkah-langkah nya dengan baik. Tidak mengecek indicator suhu, sehingga saat kondisi suhu heater tidak sesuai tetapi produksi masih tetap dilakukan, dan kurang konsentrasi sehingga produk yang menurut operator sudah sesuai spesifikasi namun di bagian Quality Control produk tersebut dinyatakan Cacat.

\subsection{Mesin}

Produk cacat jenis silver st disebabkan oleh pemanasan yang berlebih saat pemanasan biji plastik dilakukan oleh heater. Untuk menghindari panas yang berlebih didalam mesin injection juga terjadi proses pendinginan material yang terjadi ketika screw pada barrel bergerak kebelakang untuk isi ulang (Charging) plastik cair yang akan dialirkan ke nozzle pada siklus selanjutnya, gerakan dari screw di hasilkam oleh drive unitdalam mesin yang masih menggunakan Hydraulic system (sistem pompa) dan dikontrol oleh Transmission Unit jika kerja kedua bagian tersebut tidak optimal maka plastic cair akan terlalu lama berada pada heater sehingga terjadi pemanasan yang berlebihan. Untuk itu perlu perbaikan dan pengecekan berkala pada Hydraulic systemdan Transmission Unit, terutama pada Hydraulic system karena harus dipastikan tidak ada celah sehingga oli keluar dari sistem pompa.

\subsection{Data Variabel \\ 4.5.1. Menentukan Stabilitas Proses}

Variabel Panjang jari - jari (POW) untuk mengetahui stabilitas proses produksi dapat menggunakan peta control dengan mengidentifikasikan batas - batas pengendaliannya, Uji hipotesis satabilitas panjang jari - jari (POW).

\begin{tabular}{|c|c|}
\hline Nilai sigma & $=3,22$ \\
\hline USL & $=74$ \\
\hline $\mathrm{T}$ & $=70$ \\
\hline LSL & $=66$ \\
\hline$\underline{S}$ & $=1,9518$ \\
\hline $\bar{X}$ & $=70,272$ \\
\hline
\end{tabular}

Data diatas kemudian di masukan kedalam rumus sebagai berikut :

$$
\begin{aligned}
& S_{\max }=\left[\frac{1}{2 \times \text { Nilai kapabilitas sigma }}\right] \mathrm{X}(\mathrm{USL}-\mathrm{LSL}) \\
& S_{\max }=\left[\frac{1}{2 \times 3.22}\right] \mathrm{X}(74-66) \\
& S_{\max }=1,553 \times 8=1,242 \ldots \ldots \ldots \ldots \ldots \ldots(1)
\end{aligned}
$$




\subsubsection{Uji hipotesis satabilitas diameter dalam (A)}

$\begin{array}{ll}\text { Nilai sigma } & =2,60 \\ \text { USL } & =65 \\ \mathrm{~T} & =64 \\ \mathrm{LSL} & =63 \\ \frac{\mathrm{S}}{\bar{X}} & =0,60 \\ & =64,30\end{array}$

Data diatas kemudian di masukan kedalam rumus sebagai berikut :

$S_{\max }=\left[\frac{1}{2 x \text { Nilai kapabilitas sigma }}\right] \mathrm{X}(\mathrm{USL}-\mathrm{LSL})$

$S_{\max }=\left[\frac{1}{2 \times 2,60}\right] \mathrm{X}(65-63)$

$S_{\max }=0.1923 \times 2=0,3846$.

Dengan langkah yang sama didapat;

$\chi_{\text {Hitung }}^{2}=\frac{(n-1) s^{2}}{(\operatorname{Smax}) / 2}=\frac{(100-1) 0,36}{0,1479}=240,9736$

$\chi^{2}(0.95 ; 100-1)=77,9294$.

Keputusannya adalah :

Karena nilai $\chi^{2}$ Hitung $>\chi_{\text {tabel }}^{2}$ maka $H_{0}$ diterima, berarti pada tingkat signifikansi $\alpha=0.05$ variansi panjang $\mathrm{j}$ diameter dalam (A) pada tingkat sigma 2,60 proses produksi berada dalam keadaan tidak stabil.

Uji hipotesis satabilitas diameter luar (B)

\begin{tabular}{|c|c|}
\hline Nilai sigma & $=3.59$ \\
\hline USL & $=67,5$ \\
\hline $\mathrm{T}$ & $=66$ \\
\hline LSL & $=64,5$ \\
\hline$S$ & $=0,67$ \\
\hline $\bar{X}$ & $=66,1$ \\
\hline
\end{tabular}

Data diatas kemudian di masukan kedalam rumus sebagai berikut :

$S_{\max }=\left[\frac{1}{2 x \text { Nilai kapabilitas sigma }}\right] \mathrm{X}(\mathrm{USL}-\mathrm{LSL})$

$S_{\max }=\left[\frac{1}{2 \times 3.59}\right] \mathrm{X}(67,5-64,5)$

$S_{\max }=0,1398 \times 3=0,4195$.

Dengan langkah yang sama didapat;

$Z_{\text {Hitung }}^{2}=\frac{(n-1) \mathrm{g}^{\mathrm{x}}}{(\operatorname{Smax}) 2}=\frac{(100-1) 0,4489}{0,1759}=252,65$ $\chi_{(0.95 ; 100-1)}^{2}=77,9294$

Keputusannya adalah;

Karena nilai $\chi_{\text {Hitung }}^{2}>\chi^{2}$ tabel

maka $H_{0}$ diterima,berarti pada tingkat signifikansi $\alpha=0.05$ variansi panjang diameter luar B pada tingkat sigma 3,59 proses produksi berada dalam keadaan tidak stabil.

Dari uji hipotesis ketiga variable didapat kesimpulan bahwa proses produksi tidak stabil.

Tabel 6. Kemampuan Proses dan Stabilitas Proses Data Variabel

\begin{tabular}{|c|c|c|c|c|}
\hline No & Variabel & $\begin{array}{c}\text { Stabilitas } \\
\text { proses }\end{array}$ & $\begin{array}{c}\text { Ke- } \\
\text { mampu } \\
\text { an }\end{array}$ & proses \\
\hline 1 & POW & Tak stabil & 0,675 & $\begin{array}{c}\text { Tak } \\
\text { mampu }\end{array}$ \\
\hline 2 & A & Tak stabil & 0,4975 & $\begin{array}{c}\text { Tak } \\
\text { mampu }\end{array}$ \\
\hline 3 & B & Tak stabil & 0,7374 & $\begin{array}{c}\text { Tak } \\
\text { mampu }\end{array}$ \\
\hline
\end{tabular}

\section{KESIMPULAN DAN SARAN}

\subsection{KESIMPULAN}

Berdasarkan hasil pengolahan data dan pembahasan yang telah dilakukan bahwa pada data variabeljari-jari (POW), didapat DPM sebesar 42,700, kemampuan proses $\mathrm{Cpm}=0,675$, dan proses produksi dalam kondisi tidak stabil. Untuk diameter dalam (A) harga DPMO sebesar 136.000, kemampuan proses $\mathrm{Cpm}=0,4975$, dan proses produksi dalam kondisi tidak stabil. Pada data variabel diameter luar (B) harga DPMO sebesar 18.400, kemampuan proses produksi $\mathrm{Cpm}=0,7374$, dan proses produksi dalam kondisi tidak stabil. Sedangkan pada data atribut produk cacat yang paling banyak disebabkan jenis cacat Silver st sebesar 68,78 $\%$,. Dari seluruh penyebab cacat harga DPMO 34.126 dengan nilai Sigma sebesar 3,32 .

1. Usulan perbaikan pada mesin perlu adanya perbaikan pada tekanan holding, sedangkan pada metoda diperlukan penurunan suhu heater antara $1-5^{\circ} \mathrm{C}$. 
2. Untuk mengurangi pemborosan perlu dirancang ruang Pengendali Kualitas yang dekat dengan gudang.

\subsection{SARAN}

Untuk mengurangi produk cacat atau untuk meningkatkan kualitas produk mohon dilakukan perbaikan pada mesin dan metoda seperti pada kesimpulan, sedangkan untuk mengurangi pemborosan diperlukan ruang Pengendali Kualitas.

\section{DAFTAR PUSTAKA}

Bastian, A. Perbaikan produk baju dengan pendekatan metode six sigma sebagai dasar peningkatan kualitas Yogyakarta. FTI UII. 2013.

Besterfield, D.H Quality Control, (5 th edition). Singapore . Prentice-Hall,Inc. 1998.

Brue, Greg. Six Sigma for Manager, Jakarta .Canary. 2002.

Gaspersz, V. Pedoman Implementasi Program Six Sigma Terintegrasi Dengan ISO: 9001:2000, MBNQA, dan HACCP. Jakarta. PT Gramedia Pustaka Utama. 2002.

Gasperz, V.. Lean Six Sigma. Jakarta . PT. Gramedia Pustaka Utama 2007.

George, M. L. Lean Six Sigma: Combining Six Sigma Quality With Lean Speed, New York : McGraw-Hill, 2002.

Gryna, F. Quality Planning and Analisys : From Product development Through Use (4 th edition). Singapore. McGraw Hill Int. Edition, 2001.

Harisupriyanto. Aplikasi Lean Six Sigma untuk Peningkatan Kualitas Produk. Surabaya. Institut Teknologi Surabaya, 2011.

Joko, S., Winami. dan Catur, H. Aplikasi Six Sigma DMAIC Dan Kaizen Sebagai
Metode Pengendalian Dan Perbaikan Kualitas Produk. Jurnal Teknologi Vol 4 1: 78-87, 2011.

Moses, L. dan Renanda. 2008. Peningkatan kualitas produk kertas dengan menggunakan pendekatan six sigma di pabrik kertas. Surabaya.

Pete \& Holpp. What Is Six Sigma. Yogjakarta. ANDI, 2002.

Putri. V. Analisis pengendalian kualitas produk dengan pendekatan metode lean sigma sebagai upaya peningkatan kualitas produk. Yogyakarta. FTI UII, 2013.

Sofjan, Assauri. Manajemen Operasi Dan Produksi. Jakarta . LP FE UI, 1998.

Susetyo, J., Winarni dan Hartanto. Aplikasi Six Sigma dan Kaizen Sebagai Metode Pengendalian Dan Perbaikan Kualitas Produk. Jurnal Teknologi, Volume 4 Nomor 1, Juni 2011, 61-53. 2011.

Putri, Vivialita, S. Analisis pengendalian kualitas produk dengan pendekatan metode lean sigma sebagai upaya peningkatan kualitas produk, Yogyakarta. FTI UII, 2013.

Wieke,R., Nasir dan Farela, C. Implementasi Metode Lean Six Sigma Sebagai Upaya Meminimasi Waste Pada Pt. Prime Line International.Jurnal Teknologi 1-4, 2012. 